they provide 152 beds for the short- and long-term care of the mentally handicapped in Rotherham, which has a population of 255,000. The Local Authority Social Service has few hostels and group homes which together offer a total of less than five short-term care places. The weekend respite care does a lot of good to parents, but what does it do to the handicapped person, the recipient?

The handicapped person may find himself in a strange ward if the weekend respite has not been booked in advance, or if no bed was available in the usual ward by the time the request is made. He is in on Friday and out on Monday. During this time he would daily have come across, at the least, three different care givers and put up with many other clients, some worse than himself in terms of self-care skills, behaviour and the degree of physical handicap. There is just the time to scrutinize the environment, learn a few of its rules and adapt, and then it is 'goodbye'. The chances are he may have seen no doctor, had no physical examination or a routine clinical investigation. His admission is for a social reason: 'the bed and breakfast use of the hospital', as some call it.

The weekend respite does something to the consultant also. The consultant or the doctor in charge of the Unit is left in a dilemma. In Rotherham, most of these admissions are arranged between the community nurse and parents. Medical secretaries book them in liaison with social workers and community nurses in a few other places I know of. For days after their discharge, the consultant may not know of the clients who have been in for the weekend respite. This is particularly true when there are no junior doctors or when the client is on no medication. Should there be a cause for litigation for negligence during the respite care, or an unidentified diabetic who goes into a coma soon after discharge on Monday morning, who takes the responsibility?

In the above instance, the client was in a hospital and under a consultant, at least, on the HMRI (DHSS Return Form). Should the same happen in a Social Services hostel or in a family home accepting handicapped persons for weekend respite care, the judgement of the public or of a coroner would certainly be different.

There is a need for the transfer of the weekend respite care to selected and willing families. The receiver of the care, by constantly using the same family, may stand to gain more benefits. Well staffed small units in Local Authority Social Service hostels may be a second choice, especially where the degree of handicap is not severe. As for the hospital and hostels, short-term admissions for assessment, treatment, training and other respite should continue to be available for the mentally handicapped.

In terms of cost effectiveness, the suggested transfer may not be cheaper; but the handicapped person will stand to gain, his parents breathing space still assured. But until then, some consultants will continue to live with their dilemma. I would welcome comments from colleagues.

B. N. NwULU

Beechcroft

Oakwood

Moorgate Road, Rotherham

\section{Self-mutilation and Klinefelter's Syndrome}

\section{Dear Sirs}

In his recent letter (Bulletin, April 1985, 9, 83), Dr Michael Simpson, writing from Durban, seems to be rather peeved that you are giving space to the correspondence on this subject, to the extent that he asks: 'Why are we discussing this combination at all?'

I presume that he is not really suggesting that you, Sirs, should attempt to censor scientific discussion. My sense is that he is implying that this combination could have arisen by chance. Of course, this is one of the null hypotheses that my colleagues and I would like to test eventually by inferential statistics in the conventional way (Siegel'). However, we are still at the descriptive stage of scientific enquiry, rather than at the hypothesis testing stage.

One of the advantages of having the courtesy of your columns is that we are now able to contact all those who are writing in with further examples. Drs Stawski and Farmer from this department are approaching the correspondents with a systematic list of questions about the characteristics of the patients they have reported. I hope that this revelation will not prevent others from writing in! The answers will then enable us to formulate more precise hypotheses for the statistical analysis.

Your readers could be of assistance in a further way. I am not sure what the exact base rates of prevalence are for Klinefelter's Syndrome, and still less for self-multilation. If anyone could help us with figures for these frequencies it would help enormously.

\section{St Mary's Hospital}

London W2

R. G. Priest
REFERENCE

ISIEgel, S. (1956) Nonparametric Statistics for the Behavioral Sciences. New York: McGraw Hill.

\section{Italian psychiatry}

\section{DeAr SirS}

Italy must have a very different pattern of psychiatric disturbance to that in Britain. I assume from Dr Johl's article (Bulletin, April 1985, 9, 73-74) that psychosis does not occur, and that until liberated by Law No 180, Italian mental hospitals were entirely filled with unjustifiably detained patients with non-psychotic disturbances. If this was the case, then 'Democratic Psychiatry' with its emphasis on self-determination and its lack of reliance on drugs, is to be welcomed.

I suspect, however, that mental illness occurs in Italy just as frequently as it occurs here. The fallacy exemplified by $\mathrm{Dr}$ Johl's article is to treat all forms of psychological disturbance as one and from that premise to argue for a single approach to psychiatric treatment. Dr Johl clearly favours sociological reductionism over biological reductionism, equating the former with democracy, humanitarianism and libertanianism and the latter with professional domination and repression.

Perhaps I am suffering from 'false consciousness' or have been indoctrinated by the medical profession, but I am unable 